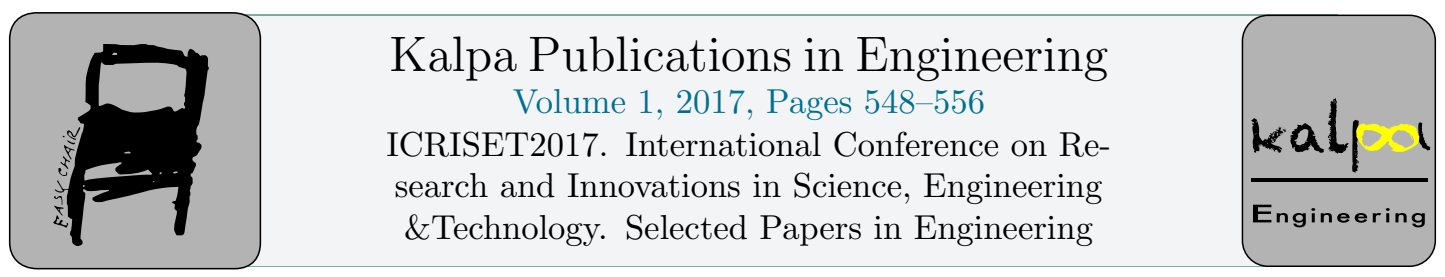

\title{
Feeding and Gating System Design and Simulation of Flange Roller of Hydrators for Yield Melioration P.D.Chauhan ${ }^{1}$ Mohit Anuvadiya ${ }^{2}$ Vivek Chauhan ${ }^{3}$ \\ ${ }^{1}$ Assistant Professor, ${ }^{2,3}$ B.E. Students, Production Engineering Department BVM Engineering College, Vallabh Vidyanagar, Gujarat, India pdchauhanebvmengineering . ac. in
}

\begin{abstract}
The aim of this paper is showing the advantage of simulation technology in Casting. Casting simulation technique is widely used in foundries and casting industries. Casting simulation simulates the real casting phenomenon and gives a virtual casting process as molten metal flow in mould cavity with respect to time and direction. This paper explains the methods and techniques of feeding \& gating system uses to increase the yield of casting in the company. On the basis of the own research it can be stated, that introducing the simulation software bring the great changes in the company, for example: product improvement by prevention of defects, increasing of effectiveness and efficiency in the processes, reduction in timing, proper utilization of material, grater quality, less cost to fulfill defects.
\end{abstract}

Keywords-Runner, Riser, Sprue, Sprue base, Gating System, Caine's method, Crack, Simulation

\section{Introduction}

Simulation simulates the real casting phenomenon using a computer program. It consists of set of mathematical equations. Casting process simulation has become an invaluable tool in the production of economical and high performance cast components. Its application by experienced and knowledgeable operators leads to reduced castings defects, casting yield improvement, and reduced trial and error iteration in development of a casting's optimization. Increasingly casting simulation being used as a collaborative tool between component designers and casting producers to reduce lead times, to develop casting friendly component designs, and to produce better castings. [11] 
Quality improvement: Improvement in quality improves the reliability of casting and reduces the excess cost of defective casting and other resources cost. The quality improvement can be obtained from simulation. [7]

Yield improvement: With simulation technique, the casting process and method is optimized in short time. And also the casting process is optimized there will be very lesser wastage thus it results in yield improvement, reduces the effective melting cost per casting, and increases the net production capacity. [4]

Rapid development: Simulation of casting is virtual process so there is no scrap material and other wastages. Casting through virtual trials eliminates the wastage of production resources, and gives opportunity to foundry to take high order.

\subsection{About Product: Flange Roller for Hydrator}

Flange Roller is with flange rings that are non-separable units, designed for application where there are axial loads, but no lateral (axial) support surfaces. The flange rings accommodate these axial loads, which are included when shafts are not horizontal or aligned properly. Depending on the design of the supports rollers, the flange rings are pressed-on or loose. [8]

\section{Product Description:}

- $\quad$ Product Weight:- $862.85 \mathrm{~kg}$

- Material:- EN-24 STEEL

- Tensile Strength:- $1.982 \times 10^{3} \mathrm{~N} / \mathrm{mm}^{2}$

- Density:- $7850 \mathrm{~kg} / \mathrm{m}^{3}$

- Hardness :-220 BHN [8]

\section{Chemical Composition:}

- Carbon

- Manganese

$0.45-0.70$

- Silicon

$0.15-0.35$

- Sulphur

$0.035 \max$

- Phosphorus

$0.04 \mathrm{max}$

- Nickel

$1.30-1.70$

- Chromium

$1.00-1.40$

- Molybdenum 


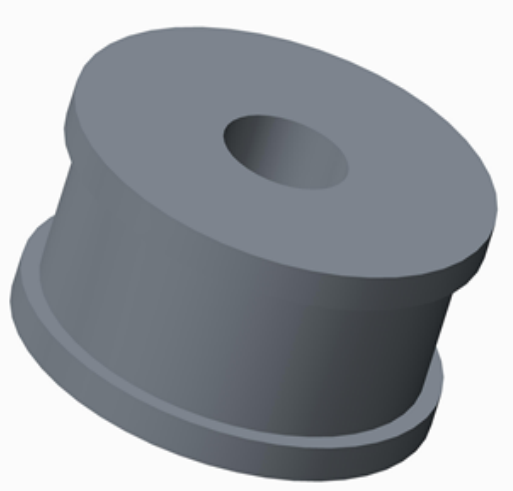

\section{Methodology}

- Method used is "Clain's Method".[1]

- Due to accurate performance we decided to use Caine's method for designing top riser.

- Performed simulation using Pro-Cast software. [11]

\subsection{Calculation of Freezing Ratio and Riser Volume:}

- Volume of Casting $=109918722.30 \mathrm{~mm}^{3}$

- Surface Area of Casting $=1865023.365 \mathrm{~mm}^{2}$

- Solidification time, $\mathrm{t}_{\mathrm{s}}=\mathrm{K}\left(\frac{\mathrm{V}}{\mathrm{SA}}\right)^{2}$

$$
\begin{aligned}
& =1.43 \times 10^{4}\left(\frac{109918722.30}{1865023.365}\right)^{2} \\
& =49.85 \mathrm{sec}
\end{aligned}
$$

- Freezing ratio, $\mathrm{X}=\frac{\mathrm{a}}{\mathrm{Y}-\mathrm{b}}+\mathrm{c}=\frac{0.10}{\mathrm{Y}-0.03}+1$

- Freezing ratio, $\mathrm{X}=\frac{(\mathrm{SA} / \mathrm{V}) \text { casting }}{(\mathrm{SA} / \mathrm{V}) \text { riser }}=\frac{0.01696}{1.25 \mathrm{\pi D}^{2} / 0.25 \pi \mathrm{D}^{3}}$

$$
=3.3945 \times 10^{-3} \mathrm{D}
$$

- $\mathrm{Y}=$ Riser Volume/Casting volume

$$
\begin{aligned}
& =\frac{0.25 \pi \mathrm{D}^{3}}{109918722.3} \\
& =7.1416 \times 10^{-9} \mathrm{D}^{3}
\end{aligned}
$$

- Putting the value of $X$ (from eq.2) and $Y$ (from eq.3) in eq.1

We get diameter of riser, $\mathrm{D}=377.7249 \mathrm{~mm}$ [4][6]

Riser Volume, $\mathrm{V}_{\mathrm{r}}=4.230546 \times 10^{7} \mathrm{~mm}^{3}$

\subsection{Comparing it with existing system:}

- Riser Dia. $=406.4 \mathrm{~mm}$

- Riser Height $=304.8 \mathrm{~mm}$

- $\quad$ Riser volume $=3.95 \times 10^{7} \mathrm{~mm}^{3}[8]$ 
- After comparing the data related to total riser volume we can say that total riser volume is sufficient.

\subsection{Calculation for Gating System:}

- Pouring Time of Molten metal:

Pouring Time $=(2.4335-0.3953 \times \log \mathrm{W}) \times \sqrt{\mathrm{W}}[2]$

Where, $\mathrm{W}=$ Mass of Casting (Not including Riser)

$$
=862.85 \mathrm{~kg}
$$

So, Pouring Time $=(2.4335-0.3953 \times \log 862.85) \times \sqrt{862.85}$

$$
=37.39 \mathrm{sec}
$$

- Mass Flow Rate:

Mass flow Rate $=\delta \mathrm{A}_{1} \mathrm{v}_{1}$

$$
=33.121726 \mathrm{~kg} / \mathrm{s}
$$

- Effective Height of Sprue:

$$
\text { Effective height }=\mathrm{H}-\frac{\mathrm{C}}{2}=74.465-\frac{\mathrm{C}}{2}
$$

$$
=561.1175 \mathrm{~mm}
$$

Where, $\mathrm{H}=$ total height of casting cavity and riser

$$
\mathrm{C}=\text { height of casting cavity }
$$

- Chock Area:

$$
\begin{aligned}
\text { Chock Area } & =\frac{\mathrm{W}}{\delta \mathrm{tc} \sqrt{2 \mathrm{gh}}} \\
\qquad & =\frac{862.85}{7000 \times 37.39 \times 0.90 \times \sqrt{2 \times 9.81 \times 0.56117}} \\
\quad & 1.104 \times 10^{-3} \mathrm{~m}^{2} \\
\text { Where }, & \\
\mathrm{W} & =\text { Weight of Casting, } \\
\delta & =\text { Density of Metal, } \\
\mathrm{t} & =\text { Metal Pouring Time }, \\
\mathrm{g} & =\text { gravity acceleration }=9.81 \mathrm{~m} / \mathrm{s}, \\
\mathrm{c} & =\text { efficiency co-efficient for bottom gating }
\end{aligned}
$$

- Pouring Basin:

Pouring Basin Height $=74.467-56.1175$

$$
\begin{aligned}
& =18.345 \mathrm{~cm} \\
& =183.45 \mathrm{~mm}
\end{aligned}
$$

- Velocity at Top of Sprue:

$$
\begin{aligned}
\mathrm{V}_{1}^{2}-\mathrm{V}_{0}{ }^{2}=2 \mathrm{gh}_{1} & \text { [13] } \\
\text { Here, } \mathrm{V}_{0} & =0 \\
\text { So, } \mathrm{V}_{1} & =\sqrt{2 \times 9.81 \times 0.18345} \\
\mathrm{~V}_{1} & =1.81971 \mathrm{~m} / \mathrm{s}
\end{aligned}
$$

- Velocity at Chock:

Same as above equation,

$$
\begin{aligned}
\mathrm{V}_{2} & =\sqrt{2 \times 9.81 \times 0.74467} \\
& =3.822 \mathrm{~m} / \mathrm{s}
\end{aligned}
$$

- According to Volume Flow Rate,

$$
\text { (Volume })_{\text {input }}=(\text { Volume })_{\text {output }}
$$

$$
\mathrm{V}_{1} \mathrm{~A}_{1}=\mathrm{V}_{2} \mathrm{~A}_{2}
$$

We have the values of $\mathrm{v}_{1}, \mathrm{v}_{2}$ and $A_{2}$

So, $A_{1}=2224.0937 \mathrm{~mm}^{2}$ 
Now, Area $\mathrm{A}_{1}=\frac{\pi}{4} \times \mathrm{d}_{1}^{2}$

$\mathrm{d}_{1}=53.228 \mathrm{~mm}$

- $\quad$ Chock Area $\mathrm{A}_{2}=\frac{\pi}{4} \times \mathrm{d}_{2}^{2}$

$$
\mathrm{d}_{2}=37.4998 \mathrm{~mm} \approx 40 \mathrm{~mm}
$$

Gating Ratio $=2.04: 1: 0.97$

- Sprue Well Calculation:

Sprue Well Area $=5 \times$ Chock Area

$$
\begin{aligned}
& =5 \times 1103.9 \\
& =5519.5 \mathrm{~mm}^{2}
\end{aligned}
$$

So, Sprue Area $=\pi \mathrm{r}^{2}=5519.5 \mathrm{~mm}^{2}$

So, $\mathrm{r}=41.92 \mathrm{~mm}$

So, $\mathrm{d}=83.85 \mathrm{~mm}$

Sprue base well Height $=$ Sprue base well Diameter

So, $\mathrm{H}=83.85 \mathrm{~mm}$

- Ingate calculation:

$\mathrm{A}=\pi \mathrm{r}^{2}=0.97 \times 1103.9$

$\mathrm{r}=18.46 \mathrm{~mm}$

So, Gate Diameter $\mathrm{d}=36.92 \mathrm{~mm} \approx 40 \mathrm{~mm}$

- Yield Calculation:

$$
\begin{aligned}
\text { Yield } & =\frac{\mathrm{V}_{\mathrm{c}}}{\mathrm{V}_{\mathrm{c}}+\mathrm{V}_{\mathrm{r}}} \\
& =\frac{10.9918722 \times 10^{7}}{(4.230546+10.9918722) \times 10^{7}} \\
& =72.19 \%
\end{aligned}
$$

The yield or efficiency of a casting is defined as the weight of the casting divided by weight of total amount to be poured [6]. Risers can add a lot to the total weight being poured. So it is important to optimize the size and shape. Here $72 \%$ yield shows that the size of risers and gating system are optimum and hence the less metal wastage in other than casting part. [7]

\section{- Comparing with existing Gating data:}

$>$ Sprue diameter : $50.8 \mathrm{~mm}$

$>$ Sprue Height $: 513.54 \mathrm{~mm}$

$>$ Gating Diameter: $38.1 \mathrm{~mm}[8]$ 


\section{Riser and Gating System}
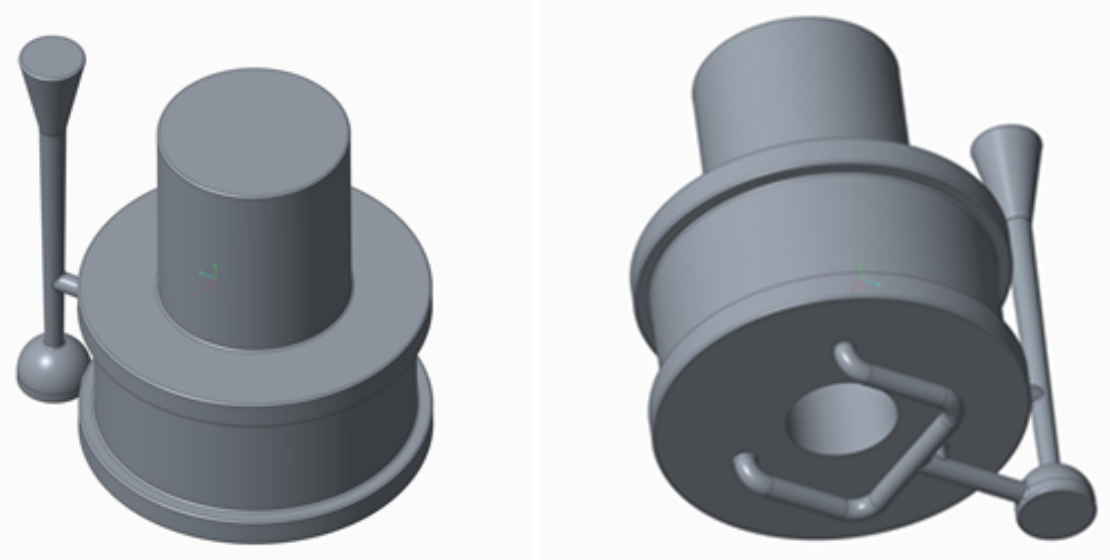

\section{Result}

4.1 Temperature Analysis of the Product:

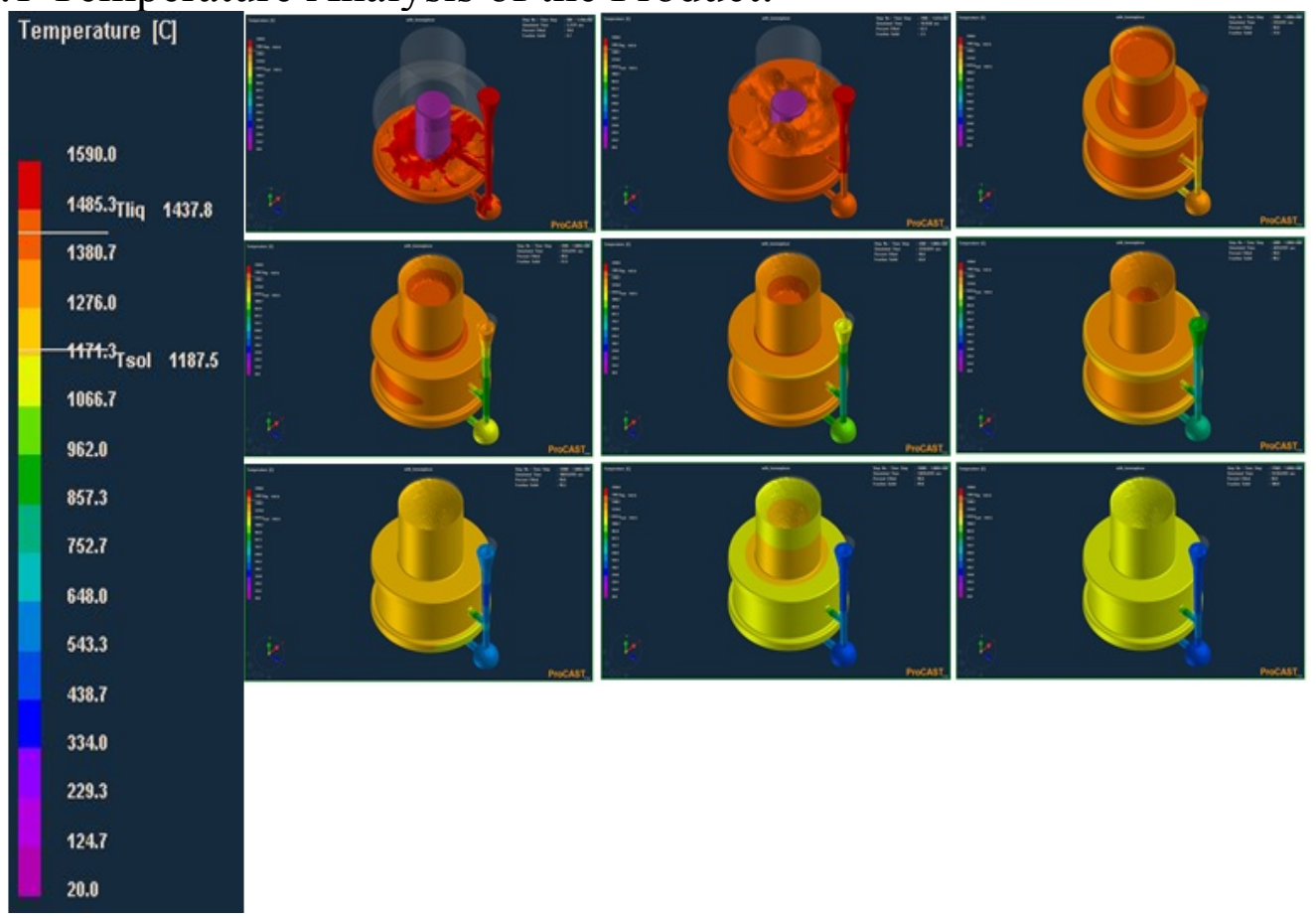


4.2 Cracks in Re-design System:

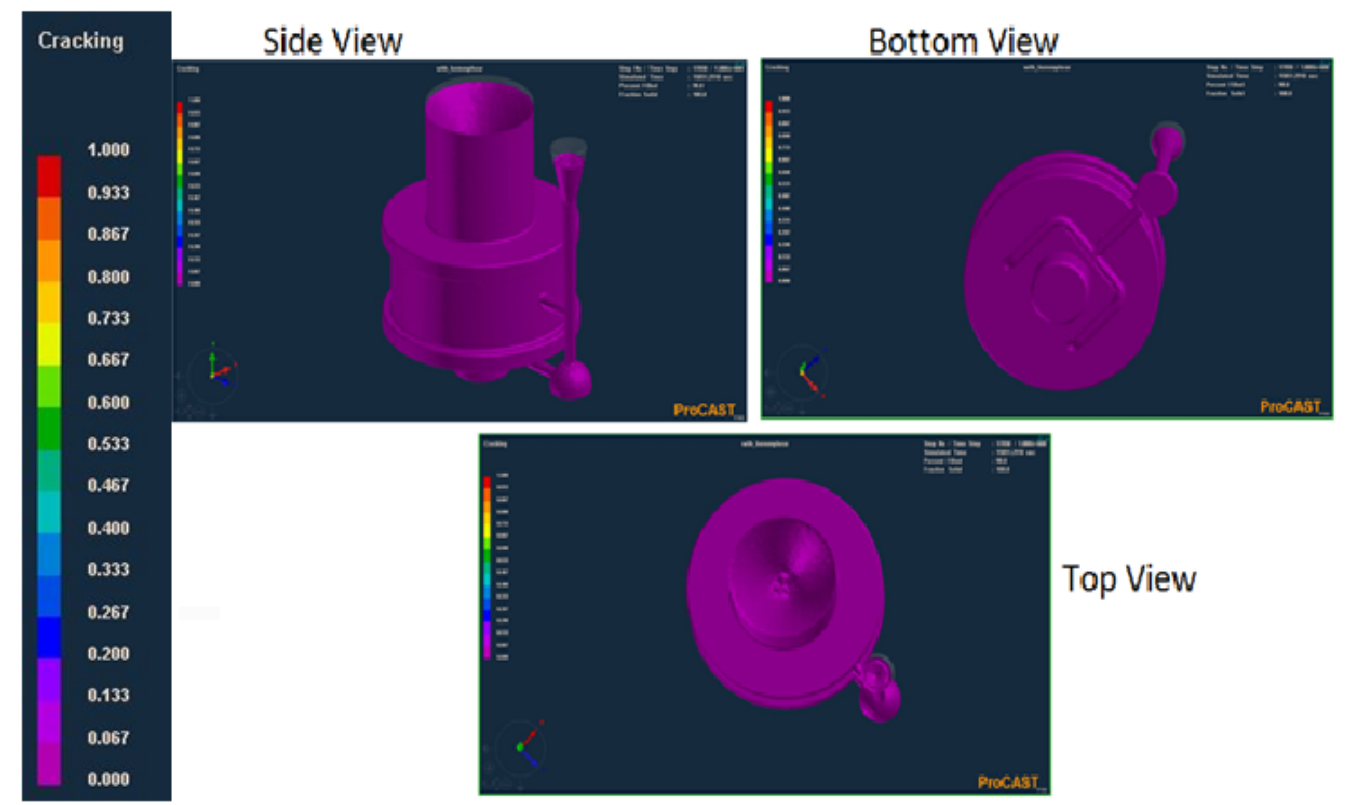

4.3 Filling Time Analysis:

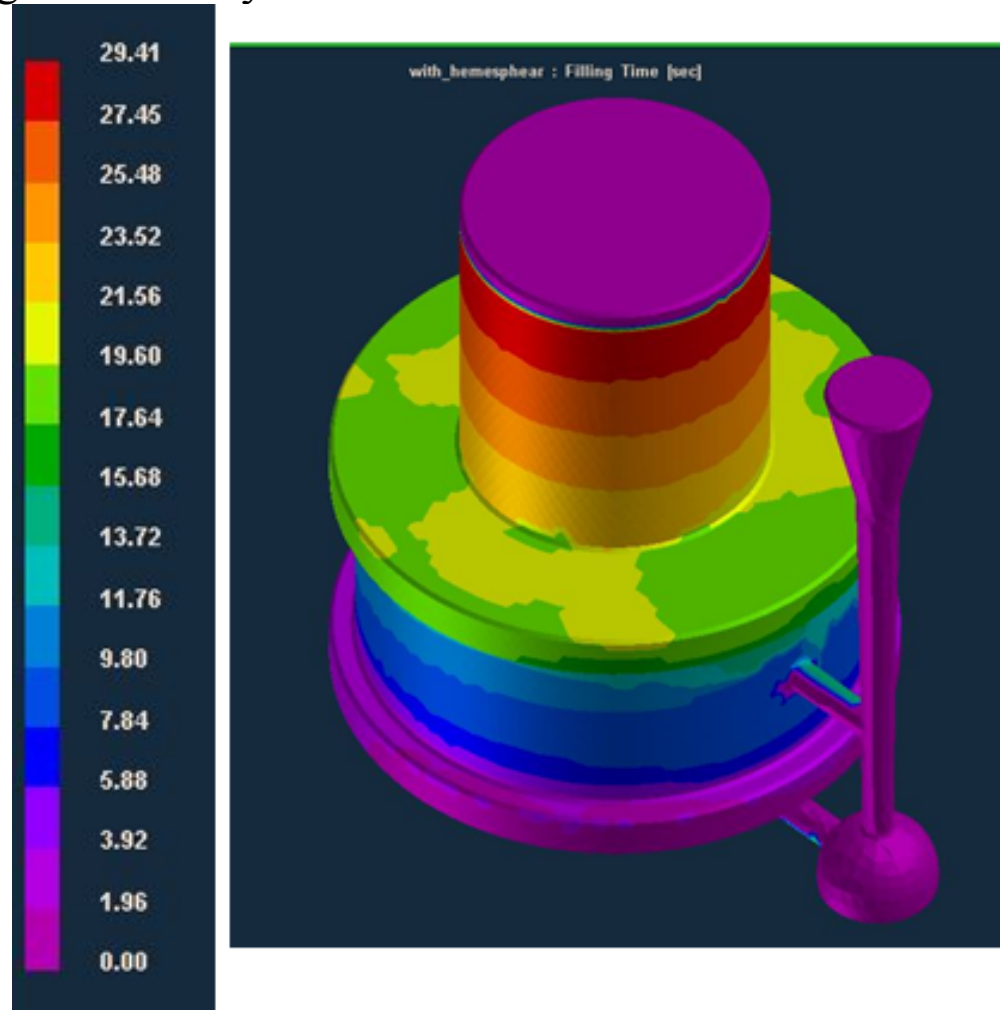


4.4 Fraction Solid Analysis:

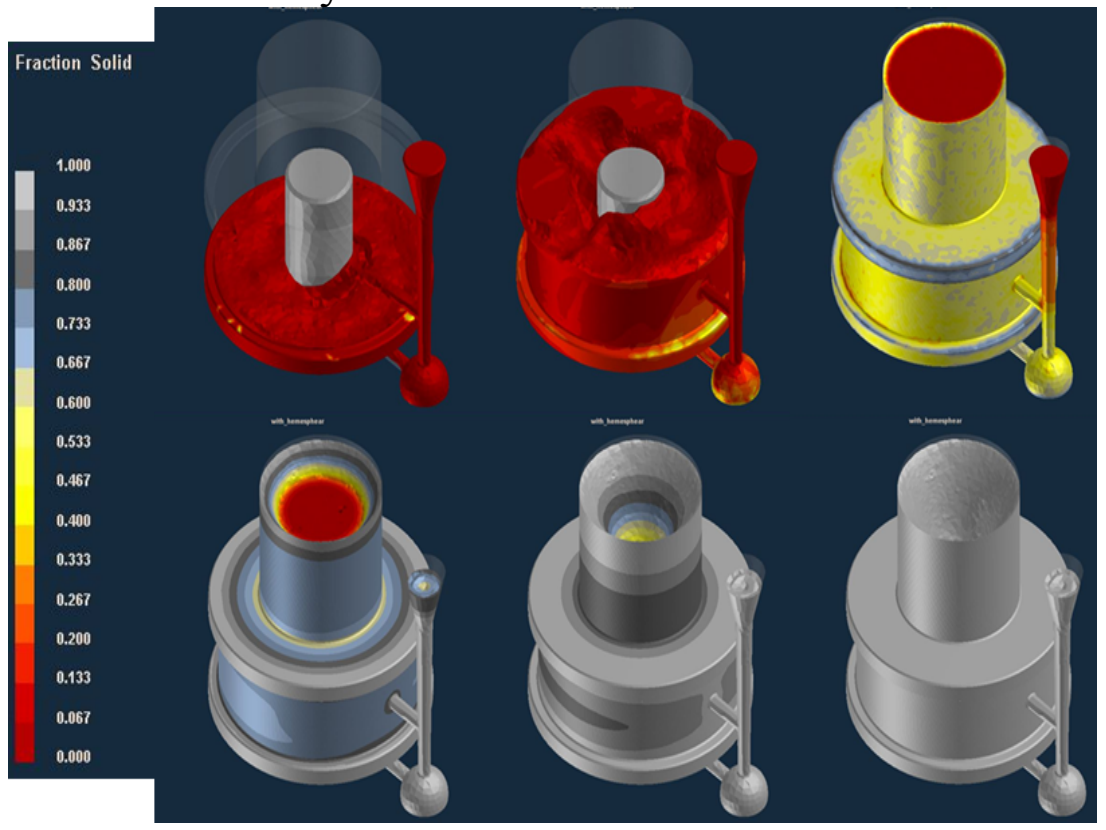

4.5 Final Product image:

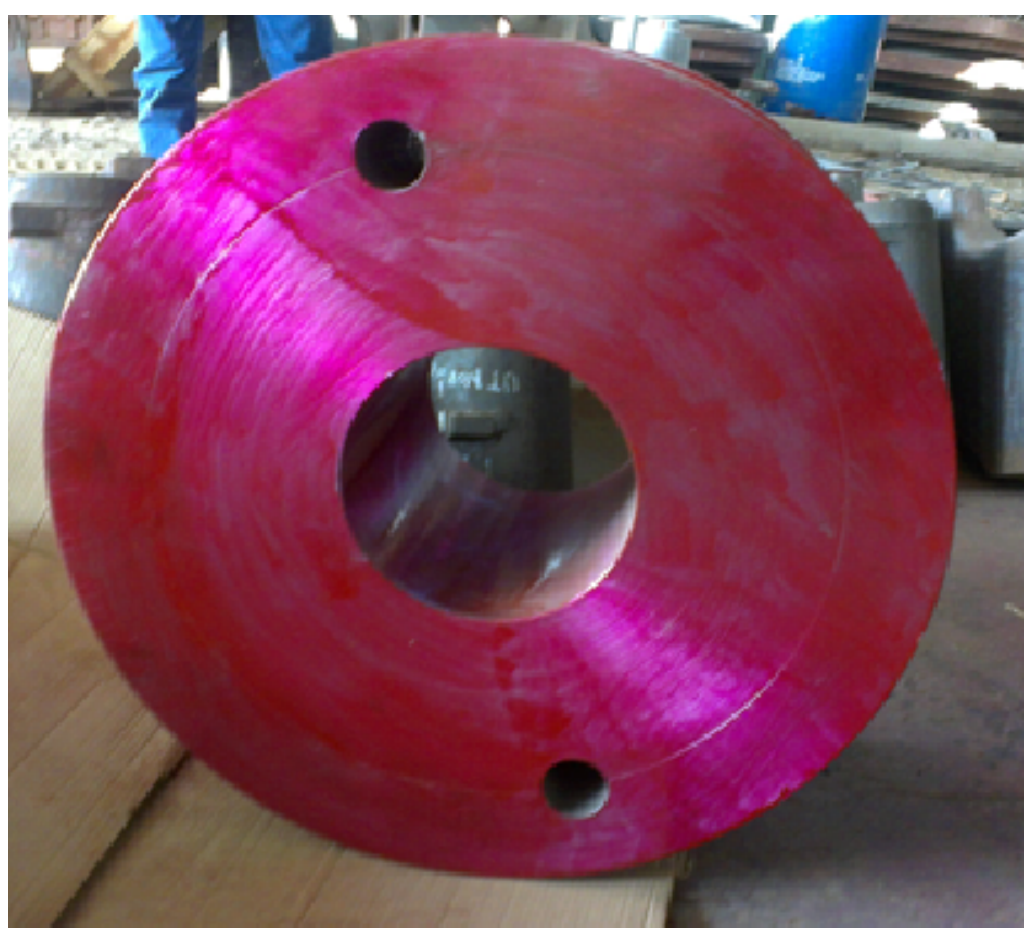




\section{Conclusion}

After referring different reference books and number of examples of complex shaped product we made calculation for feeding \&gating system design for Flange Roller of Hydrator. According to calculation and suggestion of industry, we decided to place risers with exothermic sleeve as illustrated in optimal solution to achieve following benefits like comparatively higher yield, Favorable temperature gradient, suitable for industry's methodology and easy removal of risers

In Future, the obtained result will be implemented in real time to produce defect free casting of similar products.

\section{Acknowledgement}

The authors wish to acknowledge the support of the esteemed industry Suryadeep Alloy Steel Castings Private Limited and its benevolent owner Mr. Pritesh Shah (Engineer) for this research work.

\section{References}

P. N. Rao, Manufacturing Technology (Volume-1), Tata McGrawHill, Second Edition, 2002.

R. Wlodawer, Directional Solidification of Steel Castings, Pergamon Press, First Edition.

J. R. Brown, Foseco Ferrous Foundry man's Handbook, Butterworth-Heinemann, First Edition,2000.

M. Blair, Feeding and Risering Guidelines for Steel Castings, Steel Founders' Society of America.

P. Beeley, Foundry Technology, Butterworth-Heinemann, SecondEdition,2001

O.P.Khanna, foundry technology

Metal Casting from web-source: $\underline{w w w}$.themetalcasting.com

Product manufactured by Suryadeep Alloy Steel Casting pvt.Ltd. From websource: www.suryadeepalloy.com

T.V.Rammana Rao, Metal Casting Principles and practice, New Age International (P) Ltd.

Metal Properties from Web source: www.steelexpress.co.uk

Pro Cast software information from web source:www.esi-group.com

Principles of Metal Casting" by Heine R.W.,Loper C.R. and Rosenthal P.C.

Fundamental of Metal Casting by Mukharjee P.C. 